Check for updates

Cite this: RSC Adv., 2017, 7, 22263

Received 25th February 2017

Accepted 5th April 2017

DOI: 10.1039/c7ra02349a

rsc.li/rsc-advances

\section{Iron phosphide nanocrystals decorated in situ on heteroatom-doped mesoporous carbon nanosheets used for an efficient oxygen reduction reaction in both alkaline and acidic media $\uparrow$}

\author{
Xueyan Xu, Chengxiang Shi, Rui Chen and Tiehong Chen (DD * \\ Oxygen reduction catalysts based on heteroatom-doped mesoporous carbon nanosheets loaded with \\ highly crystalline FeP nanoparticles (FeP@FePNCs) were fabricated using a simple, one-step \\ carbonization-phosphization methodology. The obtained FeP(FePNCs exhibited outstanding catalytic \\ activity and durability towards the oxygen reduction reaction (ORR) in alkaline media. Moreover, the \\ FeP@FePNCs also displayed high-performance in acidic media. The remarkable ORR activity originates \\ from the synergetic effects between the embedded FeP nanoparticles and the heteroatom-doped \\ carbon structures. Moreover, the porous structure, high specific surface area, and electron conductivity \\ can contribute to enhance the ORR performance.
}

\section{Introduction}

Fuel cells as electrochemically friendly energy storage and conversion devices are very important in the green energy field due to their high efficiency, scalability, reversibility and reduction of the negative impact of climate change. ${ }^{1,2}$ In particular, polymer electrolyte membrane fuel cells (PEMFCs) are currently regarded as one of the most reliable sustainable energy conversion devices for transport, stationary, and portable applications..$^{3-6}$ However, the sluggish oxygen reduction reaction (ORR) at the cathode presents a bottleneck to the largescale commercialization of PEMFCs. ${ }^{7,8}$ Tremendous efforts have been devoted towards the discovery and design of highly efficient and sustainable electrocatalysts for the ORR. To date, Pt-based electrocatalysts ${ }^{9,10}$ have been considered as the most suitable electrocatalysts for the ORR; however, several drawbacks have seriously hindered their wide application, including their high-cost, scarce reserves, poor durability, and low tolerance to fuel crossover. Thus, exploring non-precious metal catalysts (NPMCs) with high efficiency and robust durability has attracted much attention.

Among the various NPMCs, one of the research interests could be heteroatom (N, P, S, B, O, or their combination) doped carbon materials. ${ }^{11-26}$ These catalysts show promising electrocatalytic activities, long term stability and good conductivity,

Institute of New Catalytic Materials Science, School of Materials Science and Engineering, Key Laboratory of Advanced Energy Materials Chemistry (MOE), Collaborative Innovation Center of Chemical Science and Engineering (Tianjin), Nankai University, Tianjin 300350, PR China.E-mail: chenth@nankai.edu.cn

$\dagger$ Electronic supplementary information (ESI) available. See DOI: 10.1039/c7ra02349a which are attributed to doping the carbon materials with heteroatoms that modify the electronic structure (such as the charge and/or spin density redistribution) of carbon and create active sites favorable for the adsorption of $\mathrm{O}_{2}$ molecules and thus facilitates the ORR process. ${ }^{27,28}$ However, few catalysts have exhibited promising potential as alternatives to the commercialized Pt/C catalysts in regard to the aspects of the typical $4 \mathrm{e}^{-}$ process and positive onset potential etc, particularly in acidic media. The involvement of transition metals will enable to significantly improve the ORR catalytic activity due to the synergetic effects between the different active species. Recently, it has been found that Fe-containing species embedded in the carbon matrix exhibit enhanced catalytic activity for the ORR, such as iron nitrides, ${ }^{29}$ iron carbides, ${ }^{30-32}$ iron oxides $^{33,34}$ and metallic iron. ${ }^{35,36}$ Recent study by Zhang et al. reported a type of novel bifunctional catalyst used for the oxygen reduction and evolution reactions based on $\mathrm{N}$ and $\mathrm{P}$ dual-doped porous carbon nanosheets comprising uniform FeP nanoparticles (NPs) embedded in the carbon layers. ${ }^{37}$ This provides a new idea for the application of iron phosphides in the ORR. However, this catalyst worked only in alkaline media, which limited its application in PEMFCs because the electrolyte used in the cells is an acidic solution. Consequently, it is highly desirable to incorporate FeP NPs into heteroatom doped carbon nanostructures to harvest more active sites, enhance the synergetic effects between them and thus, greatly improve their catalytic activity in the ORR.

Herein, we present a facile and effective route to prepare a catalyst with highly crystalline FeP NPs embedded in situ in the $\mathrm{N}$ and $\mathrm{P}$ dual-doped mesoporous carbon nanosheets (FeP@PNC); the catalyst is prepared via a simple pyrolysis step 
without post-treatment, including acid leaching and a second heat treatment, which drastically shortens the time required for the simple preparation. The electrocatalytic activities of the resulting FeP@PNC composites were evaluated towards the ORR in both alkaline and acidic media. The experimental results indicated that the FeP@PNC pyrolyzed at $900{ }^{\circ} \mathrm{C}$ exhibited a superior ORR activity and high stability, which was comparable to that of the commercial $\mathrm{Pt} / \mathrm{C}$ catalyst.

\section{Experimental}

\section{Chemicals and materials}

All reagents were of analytical grade and used without further purification. Furthermore, 1, 10-phenanthroline monohydrochloride monohydrate (Phen), $\mathrm{FeSO}_{4} \cdot 7 \mathrm{H}_{2} \mathrm{O}$ and $\left(\mathrm{NH}_{4}\right)_{2} \mathrm{HPO}_{4}$ were obtained from Aladdin Chemical (China). Melamine (Mela) and Pt/C (20\% by wt., Pt nanoparticles on a Vulcan XC-72 carbon support) catalyst were purchased from Alfa Aesar. Nafion solution (5\% in a mixture of lower aliphatic alcohols and water) was obtained from Sigma Aldrich.

\section{General synthesis of the catalysts}

In a typical procedure, $0.54 \mathrm{~g}$ of Phen was mixed with $0.21 \mathrm{~g}$ of $\mathrm{FeSO}_{4} \cdot 7 \mathrm{H}_{2} \mathrm{O}$ in $10 \mathrm{~mL}$ of ethanol with a Phen/Fe molar ratio of $3: 1$ at room temperature. Then, $1.0 \mathrm{~g}$ of $\left(\mathrm{NH}_{4}\right)_{2} \mathrm{HPO}_{4}$ and $4.0 \mathrm{~g}$ of Mela was added to the abovementioned mixture. After stirring for about $5 \mathrm{~min}$, this mixture was dried at $60{ }^{\circ} \mathrm{C}$ for $12 \mathrm{~h}$; after evaporation of the ethanol, the obtained FeP@PNC precursor was ground and subsequently carbonized at 800, 900, and $1000{ }^{\circ} \mathrm{C}$ in high-purity nitrogen atmosphere for $2 \mathrm{~h}$. The products were referred to as FeP@PNC- $T$ (with $T$ denoting the annealing temperature).

FeP@PNC-900 was ground using a ball-milling machine and agitated at $800 \mathrm{rpm}$ for $4 \mathrm{~h}$. After milling, the catalyst was leached in $0.5 \mathrm{M} \mathrm{H}_{2} \mathrm{SO}_{4}$ at $90{ }^{\circ} \mathrm{C}$ for $12 \mathrm{~h}$ to remove the FeP NPs. The resulting sample was named FeP@PNC-900-BL.

\section{Characterization}

Transmission electron microscopy (TEM) was carried out on a Philips Tecnai F20 microscope operated at $200 \mathrm{kV}$. All the samples subjected to TEM measurements were ultrasonically dispersed in ethanol and dropped onto copper grids covered with a carbon film. Raman spectra were obtained on a Lab RAMHR Raman spectrometer using laser excitation at $514 \mathrm{~nm}$. Powder X-ray diffraction (XRD) patterns were recorded on a $\mathrm{D} /$ max-2500 diffractometer (Rigaku, Japan) using $\mathrm{Cu} \mathrm{K} \alpha$ radiation $(\lambda=1.5406 \AA$ ). X-ray photoelectron spectroscopy (XPS) measurements were performed on a Thermo Fisher Scientific ESCLAB 250Xi spectrometer. Nitrogen adsorption and desorption isotherms were measured on a BELSORP-mini II sorption analyser at liquid nitrogen temperature of $77 \mathrm{~K}$. Prior to the measurements, the samples were degassed at $300{ }^{\circ} \mathrm{C}$ for $4 \mathrm{~h}$. The surface areas were calculated using the multipoint Brunauer-Emmett-Teller (BET) method. The total pore volumes were estimated from the volume adsorbed at a relative pressure $\left(P / P_{0}\right)$ of 0.98 . The pore-size distribution was calculated from the adsorption branch using the Barrett-Joyner-Halenda (BJH) method.

\section{Electrochemical measurements}

In order to prepare the working electrode, $4 \mathrm{mg}$ of sample was dispersed in $1 \mathrm{~mL}$ of $\mathrm{H}_{2} \mathrm{O}$ by sonication for at least $30 \mathrm{~min}$. Prior to use, the glassy carbon rotating disk electrode $(5 \mathrm{~mm}$ in diameter, $0.196 \mathrm{~cm}^{2}$ in surface area) was polished mechanically with $1.0 \mu \mathrm{m}$ to $0.05 \mu \mathrm{m}$ alumina powder to obtain a mirror-like surface and then washed with distilled water and allowed to dry. Then, $20 \mu \mathrm{L}$ of the resulting homogeneous suspension was carefully dropped onto a rotating disk electrode (RDE) using a pipette, and the suspension was air-dried to allow the solvent to evaporate. After drying at room temperature, $3 \mu \mathrm{L}$ of a $5 \mathrm{wt} \%$ Nafion solution was further dropped to form a protection layer against the catalyst detaching from the electrode surface; the loading was $410 \mu \mathrm{g} \mathrm{cm}^{-2}$. High-purity $\mathrm{O}_{2}$ was purged for $30 \mathrm{~min}$ at least before each test. For comparison, the benchmark commercial Pt/C (20 wt\% Pt on Vulcan XC-72) catalyst was also fabricated into electrodes using a similar procedure. The loading amount was $41 \mu \mathrm{g} \mathrm{Pt} \mathrm{cm}^{-2}$ in both alkaline and acidic media.

All electrochemical experiments were conducted on a RRDE3A (ALS, Japan) device in conjunction with a CHI660D electrochemical workstation at room temperature. The three-electrode system included a glassy carbon RDE coated with catalysts, a platinum wire auxiliary electrode, and a $\mathrm{Ag} / \mathrm{AgCl}(3 \mathrm{M} \mathrm{KCl})$ reference electrode. Before each ORR experiment, the electrolyte was purged with $\mathrm{O}_{2}$ for at least $30 \mathrm{~min}$. A flow of $\mathrm{O}_{2}$ was maintained over the electrolyte during the recording of the electrochemical measurements in order to ensure its continuous $\mathrm{O}_{2}$ saturation. The ORR activity was evaluated by cyclic voltammetry (CV) and linear sweep voltammetry (LSV) on RDE in $\mathrm{O}_{2}$-saturated $0.1 \mathrm{M} \mathrm{KOH}$ and $0.5 \mathrm{M} \mathrm{H}_{2} \mathrm{SO}_{4}$ electrolytes. All the $\mathrm{CV}$ measurements were conducted at a scan rate of $10 \mathrm{mV} \mathrm{s}^{-1}$, and the LSV curves were recorded at a scan rate of $5 \mathrm{mV} \mathrm{s}^{-1}$. The chronoamperometric measurement $(i-t)$ was used to investigate the electrode stability at a bias potential of $-0.5 \mathrm{~V}$ and $0.3 \mathrm{~V}$ ( $v s$. $\mathrm{Ag} / \mathrm{AgCl}$ ) in $\mathrm{O}_{2}$-saturated $0.1 \mathrm{M} \mathrm{KOH}$ and $0.5 \mathrm{M} \mathrm{H}_{2} \mathrm{SO}_{4}$ solutions, respectively, with a rotation rate of $1600 \mathrm{rpm}$. Then, the tolerance to the methanol crossover was tested by adding $3 \mathrm{M}$ methanol into the $\mathrm{O}_{2}$-saturated electrolyte solution. On the basis of the RDE data, the overall electron transfer number per oxygen molecule involved in the oxygen reduction reaction can be determined using the Koutechy-Levich (K-L) equation:

$$
1 / J=1 / J_{\mathrm{K}}+1 / J_{\mathrm{L}}=1 / J_{\mathrm{K}}+1 / B \omega^{1 / 2}
$$

where $J$ is the measured disk current density. $J_{\mathrm{K}}$ and $J_{\mathrm{L}}$ represent the kinetic and diffusion limiting current densities, respectively. $\omega$ is the electrode rotating rate. $B$ is determined from the slope of the $\mathrm{K}-\mathrm{L}$ plots based on the Levich equation as given below:

$$
\begin{gathered}
B=0.2 n F\left(D_{\mathrm{O}_{2}}\right)^{2 / 3} v^{-1 / 6} C_{\mathrm{O}_{2}} \\
J_{\mathrm{K}}=n F k C_{\mathrm{O}_{2}}
\end{gathered}
$$


where $n$ represents the transferred electron number per oxygen molecule, $F$ is Faraday constant $\left(F=96485 \mathrm{C} \mathrm{mol}^{-1}\right), D_{\mathrm{O}_{2}}$ is the diffusion coefficient of $\mathrm{O}_{2}$ in $0.1 \mathrm{M} \mathrm{KOH}\left(D_{\mathrm{O}_{2}}=1.9 \times 10^{-5} \mathrm{~cm}^{2}\right.$ $\left.\mathrm{s}^{-1}\right), v$ is the kinetic viscosity $\left(v=0.01 \mathrm{~cm}^{2} \mathrm{~s}^{-1}\right), C_{\mathrm{O}_{2}}$ is the bulk concentration of $\mathrm{O}_{2}\left(C_{\mathrm{O}_{2}}=1.2 \times 10^{-6} \mathrm{~mol} \mathrm{~cm}^{-3}\right)$, and $k$ is the electron-transfer rate constant. ${ }^{38}$ The values of $C, D$ and $v$ are the same in both the $0.1 \mathrm{M} \mathrm{KOH}$ and $0.5 \mathrm{M} \mathrm{H}_{2} \mathrm{SO}_{4}$ solutions. ${ }^{39}$

\section{Results and discussion}

The FeP@PNC was synthesized via the polymerization of $\left[\mathrm{Fe}(\mathrm{Phen})_{3}\right]^{2+}$ with Mela using $\left(\mathrm{NH}_{4}\right)_{2} \mathrm{HPO}_{4}$ for $\mathrm{P}$ doping and a subsequent carbonization step under an inert atmosphere at different temperatures. The generation of carbon and the corresponding composite can be verified by powder X-ray diffraction (XRD) analysis. The wide-angle XRD patterns in Fig. 1a show a broad diffraction peak centered at $2 \theta=26.5^{\circ}$ for FeP@PNC-800, which was attributed to the carbon (002) peak and is typical of graphitic carbon materials with a low degree of graphitization..$^{40}$ Upon increasing the pyrolysis temperature, a series of strong diffractions can be indexed to the FeP phase (JCPDS No. 71-2262), confirming the successful formation of highly crystalline FeP NPs. The remarkable suppression of the intensity of the carbon (002) peak in FeP@PNC-900 and FeP@PNC-1000 can be related to the loading of FeP on the carbon matrix with high density and dispersion.

Raman spectroscopy is an effective characterization technique used for investigating carbon materials. In Fig. $1 \mathrm{~b}$, two distinctive peaks, designated as the $\mathrm{D}$ and $\mathrm{G}$ band, can be seen at 1348 and $1591 \mathrm{~cm}^{-1}$, respectively. The $\mathrm{D}$ band originates from the hybridized vibrational mode associated with the edges of the carbons and is referred to as the disorder or defect band, whereas the $\mathrm{G}$ band is attributed to the tangential oscillations and vibrations of the $\mathrm{sp}^{2}$-hybridized carbon atoms. ${ }^{41-43}$ The peak intensity ratio of $\mathrm{D}$ to $\mathrm{G}$ band $\left(I_{\mathrm{D}} / I_{\mathrm{G}}\right)$ can be used to measure the level of disorder in a graphitic structure, signifying higher disorder for a higher $I_{\mathrm{D}} / I_{\mathrm{G}}$ value. The $I_{\mathrm{D}} / I_{\mathrm{G}}$ values were $2.28,1.49$ and 1.23 for the FeP@PNC-800, FeP@PNC-900 and FeP@PNC1000 samples, respectively (Fig. 1b). These results indicate an increase in the degree of graphitization of carbon upon increasing the pyrolysis temperature and may be favorable for electron transfer during electrocatalysis.

TEM was conducted to assess the fine structures of the carbonaceous materials. For the FeP@PNC-800 sample, no
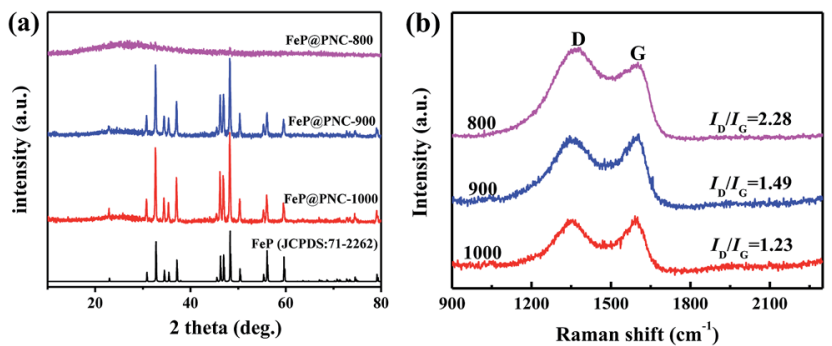

Fig. 1 (a) The XRD patterns and (b) Raman spectra of the FeP@PNC catalysts synthesized at different temperatures. detectable metal NPs were found (Fig. 2a), which was in agreement with the XRD results. The TEM images show the presence of nearly transparent carbon nanosheets, which indicate the thin thickness of FeP@PNC-900 (Fig. 2b). Moreover, highly crystalline FeP NPs and nanorods were embedded in the carbon nanosheets. Notably, the high-resolution TEM (HR-TEM) image (Fig. 2c) shows that the FeP NPs were uniformly encapsulated by the graphitic carbon shells, forming a well-defined metal oxide phosphide-graphitized carbon core-shell structure. The confinement of the FeP NPs by the outer carbon shells can enhance the close interaction between the FeP NPs and conductive carbon shells, and restrain the dissolution and agglomeration of the FeP NPs, thus enhancing the electrocatalytic activity and durability. At the same time, the lattice spacing of $0.27 \mathrm{~nm}$ was ascribed to the (011) plane of FeP (Fig. 2c). STEM-EELS mapping analysis (Fig. 3) further demonstrates the uniform distribution of both the Fe and P elements in the FeP NPs, which are successfully embedded in the carbon nanosheets. When the pyrolysis temperature was increased to $1000^{\circ} \mathrm{C}$, as seen in Fig. 2 d, the carbon coated FeP NPs were still uniformly embedded in the carbon nanosheets.

$\mathrm{N}_{2}$ adsorption-desorption measurements were conducted to provide additional insights into the textual properties of FeP@PNC-900 (Fig. S1†). The sorption isotherm is of type IV with distinct hysteresis loops of H3-type for all the FeP@PNC samples, which are characteristic of mesoporous materials. The BET surface area and total pore volume of the FeP@PNC-900 nanosheets were determined to be $724 \mathrm{~m}^{2} \mathrm{~g}^{-1}$ and $1.62 \mathrm{~cm}^{3}$ $\mathrm{g}^{-1}$, respectively, which are much larger than those observed for FeP@PNC-800 and FeP@PNC-1000. Such porous characteristics endow FeP@PNC with accessible inner active sites to allow good contact with the electrolyte and easy electrolyte diffusion, which
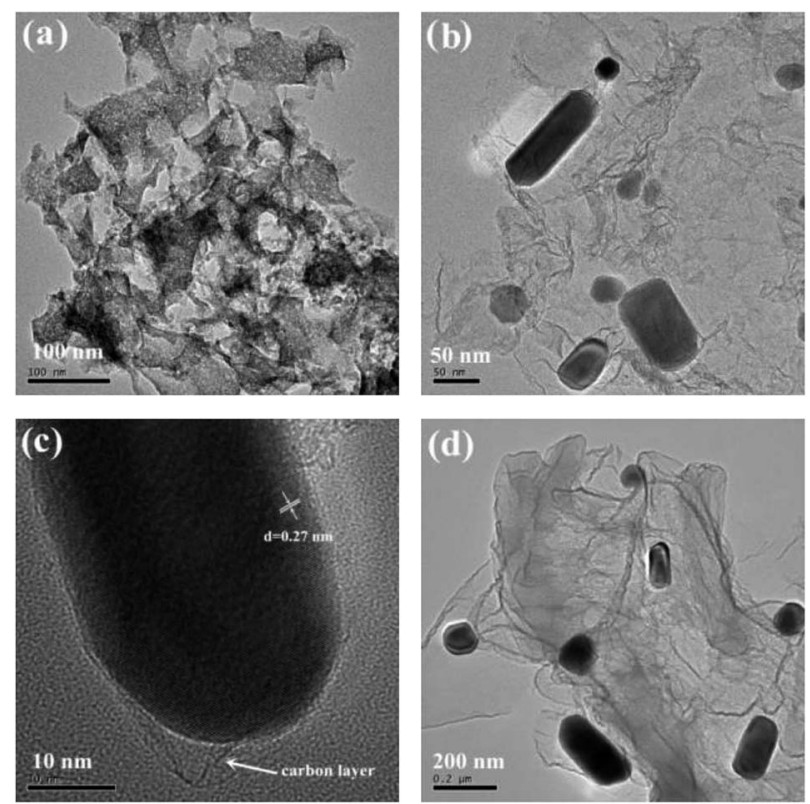

Fig. 2 The TEM images of (a)FeP(APNC-800, (b and c) FeP@PNC-900 and (d) FeP@PNC-1000. 


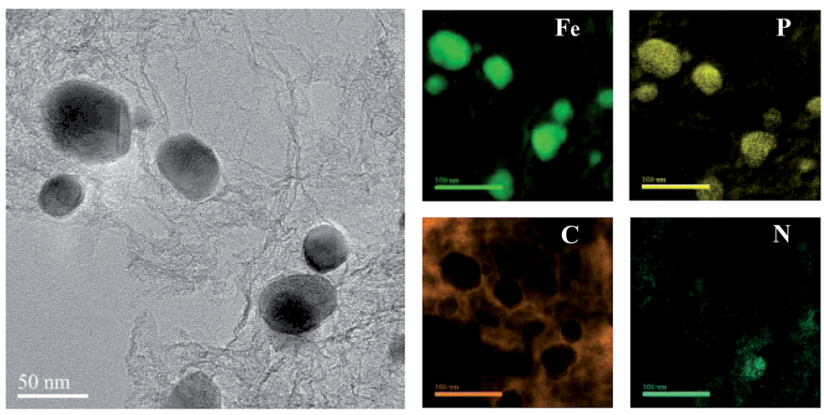

Fig. 3 The STEM image of FeP@PNC-900 and the corresponding EELS mapping images of Fe, $\mathrm{P}, \mathrm{C}$ and $\mathrm{N}$.

are favorable for the improvement in the electrochemical catalytic activity of FeP@PNC.

To further elucidate the doped elements and bonding configurations, XPS measurements (Fig. 4) were conducted on FeP@PNC- $T$. The surface survey XPS spectrum shows the presence of $\mathrm{C}, \mathrm{N}, \mathrm{O}, \mathrm{P}$ and Fe in the samples (Fig. S2 $\dagger$ ). The presence of oxygen was probably due to the physicochemically adsorbed oxygen and the residual oxygen-containing species from the precursor. Furthermore, the high-resolution $\mathrm{C}$ 1s spectrum (Fig. S3a $\uparrow$ ) can be deconvoluted into four single peaks corresponding to $284.8 \mathrm{eV}(\mathrm{C} 1, \mathrm{C}=\mathrm{C}), 285.8 \mathrm{eV}(\mathrm{C} 2, \mathrm{C}=\mathrm{N}$ and $\mathrm{C}-\mathrm{O})$, $287.6 \mathrm{eV}(\mathrm{C} 3, \mathrm{C}-\mathrm{N}$ and $\mathrm{C}=\mathrm{O})$ and $289.2 \mathrm{eV}(\mathrm{C} 4, \mathrm{O}-\mathrm{C}=\mathrm{O})$, indicating the existence of the heteroatoms in the hybrids. ${ }^{44}$ Remarkably, the significant difference in the $\mathrm{sp}^{2}$-hybridized carbon atom (C1 type; 47.1 at\%, 58.3 at\%, and 67.1 at $\%$ at $800{ }^{\circ} \mathrm{C}, 900{ }^{\circ} \mathrm{C}$ and $1000{ }^{\circ} \mathrm{C}$, respectively; Table S3†) clearly
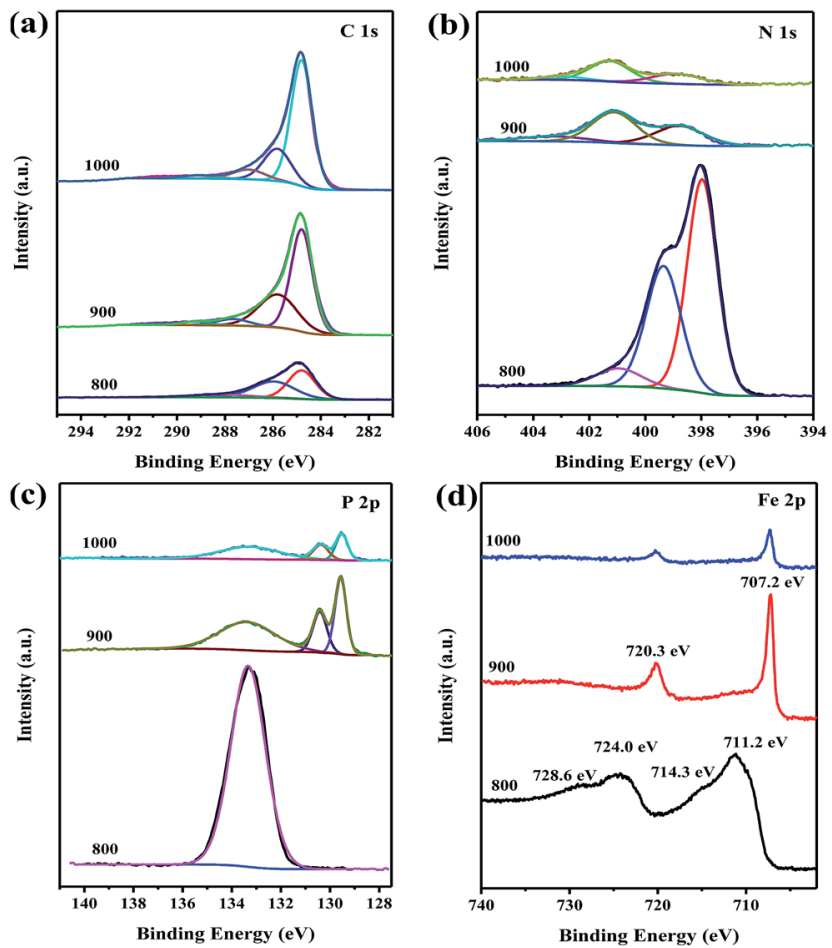

Fig. 4 The high-resolution (a) C 1s, (b) N 1s, (c) P 2p and (d) Fe 2p spectra of the FeP@PNC-T demonstrates an improvement in the degree of graphitization for the obtained FeP@PNC upon increasing the temperature. As shown in Fig. S3b, $\dagger$ the $\mathrm{N}$ 1s spectra can be deconvoluted into three peaks at $398.8,401.1$, and $403.3 \mathrm{eV}$, indicating the presence of pyridinic- $\mathrm{N}$, graphitic- $\mathrm{N}$, and oxidized-N, respectively. ${ }^{45}$ Furthermore, the total $\mathrm{N}$ content decreased from 29.04 at $\%$ to 3.10 at\% when the annealing temperature was increased from $800{ }^{\circ} \mathrm{C}$ to $1000{ }^{\circ} \mathrm{C}$ (Table S2 $\dagger$ ), due to the instability of the $\mathrm{N}$ dopant at elevated temperature. The content of $\mathrm{N}$ in various configurations is listed in Table $\mathrm{S} 3 . \dagger$ These nitrogen functional groups are indicative of the carbons that contain $\mathrm{N}$ atoms inserted in the carbonaceous backbone. The high-resolution $\mathrm{P}$ 2p spectrum of FeP@PNC-900 (Fig. S3c $\dagger$ ) shows three deconvolved peaks at $129.6 \mathrm{eV}, 130.4 \mathrm{eV}$ and 133.4, which reveal the presence of $\mathrm{P} 2 \mathrm{p}_{3 / 2}, \mathrm{P} 2 \mathrm{p}_{1 / 2}$ and $\mathrm{P}-\mathrm{C}$ bonds, respectively. ${ }^{46}$ The results indicate that $\mathrm{P}$ atoms have been successfully incorporated into the N-doped carbon nanosheets in all the FeP@PNC samples; this triggers the synergistic effects for catalyzing the oxygen redox reactions. In the Fe 2p spectrum shown in Fig. 4d, the two peaks at 707.2 and $720.3 \mathrm{eV}$ are ascribed to the $2 \mathrm{p}_{3 / 2}$ and $2 \mathrm{p}_{1 / 2}$ of $\mathrm{Fe}^{0}$ in FeP@PNC-900 and FeP@PNC-1000, while the high resolution spectra of $\mathrm{Fe} 2 \mathrm{p}$ for FeP@PNC-800 can be deconvoluted into two pairs of peaks for $\mathrm{Fe}^{3+}(714.3$ and 728.6 $\mathrm{eV})$ and $\mathrm{Fe}^{2+}$ (711.3 and $\left.724.2 \mathrm{eV}\right)$. The peaks at 707.2 and $129.6 \mathrm{eV}$ are close to the binding energy of $\mathrm{Fe}$ and $\mathrm{P}$ in FeP. These results indicate the successful synthesis of FeP particles in FeP@PNC-900 and FeP@PNC-1000.

The electrocatalytic activities of the catalysts obtained at different pyrolysis temperatures were measured in an $\mathrm{O}_{2}$-saturated $0.1 \mathrm{M} \mathrm{KOH}$ aqueous solution using $\mathrm{RDE}$ at room temperature. As shown in the CV measurements (Fig. 5a), the
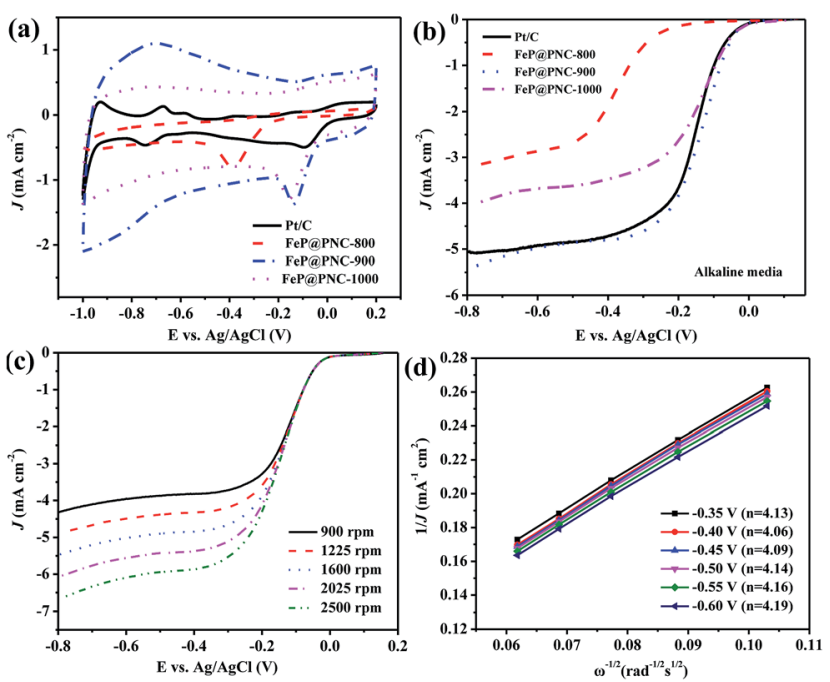

Fig. 5 (a) The CV curves obtained for the FeP@PNC-T samples and Pt/ $C$ catalysts in an $\mathrm{O}_{2}$-saturated $0.1 \mathrm{M} \mathrm{KOH}$ solution at a scan rate of $10 \mathrm{mV} \mathrm{s}^{-1}$. (b) The linear sweep voltammograms (LSVs) of FePaPNC-T and $\mathrm{Pt} / \mathrm{C}$ at a scan rate of $5 \mathrm{mV} \mathrm{s}^{-1}$ and a rotation rate of $1600 \mathrm{rpm}$. (c) The LSV curves obtained for FeP(PNC-T at a rotation rate from 900 to $2500 \mathrm{rpm}$. (d) The $\mathrm{K}-\mathrm{L}$ plots and electron transfer number (in the legend) for the FeP(aPN-900 catalyst in an $\mathrm{O}_{2}$-saturated $0.1 \mathrm{M} \mathrm{KOH}$ solution. 
ORR peaks were found at $-0.095,-0.382,-0.134$ and $-0.149 \mathrm{~V}$ in the $\mathrm{O}_{2}$-saturated $0.1 \mathrm{M} \mathrm{KOH}$ solution for Pt/C, FeP@PNC-800, FeP@PNC-900 and FeP@PNC-1000, respectively. FeP@PNC-900 had the most close cathodic reduction peak potential compared to that of commercial $\mathrm{Pt} / \mathrm{C}$, indicating its high ORR catalytic activity. Linear sweep voltammograms (LSVs) of FeP@PNC-900 for the ORR in an $\mathrm{O}_{2}$-saturated $0.1 \mathrm{M} \mathrm{KOH}$ solution at a rotation rate of $1600 \mathrm{rpm}$ were displayed in Fig. 5b. FeP@PNC-900 displayed higher ORR onset potential $(-0.054 \mathrm{~V})$ and halfwave potential $(-0.138 \mathrm{~V})$ values than FeP@PNC-800 and FeP@PNC-1000 (Table S4†), suggesting the high intrinsic ORR activity and active site density of FeP@PNC-900. With a loading of $410 \mu \mathrm{g} \mathrm{cm}^{-2}$, the ORR half-wave potential of FeP@PNC-900 was $17 \mathrm{mV}$ more than that of the commercial Pt/C (with the loading of $41 \mu \mathrm{g} \mathrm{Pt} \mathrm{cm}{ }^{-2}$ ), which was comparable with the best values obtained for the non-precious metal catalysts reported in the literature. ${ }^{47,48}$ It was noticed that the ORR current density $(J)$ with FeP@PNC-900 was larger than that found with Pt/C in the high potential regions $(>-0.3 \mathrm{~V})$, indicating its high catalytic properties for the ORR. The corresponding K-L plots within the potential range from -0.35 to $-0.60 \mathrm{~V}$ exhibited a good linearity with a rather constant slope (Fig. 5d), suggesting first-order reaction kinetics for ORR with respect to the concentration of dissolved oxygen and similar transferred electron numbers $(n)$ at different electrode potentials (Fig. 5d). ${ }^{49,50}$ The electron transfer number calculated from the slope of the K-L plots for FeP@PNC-900 catalyst is shown in the legend of Fig. 5d, suggesting that it favored a dominant $4 \mathrm{e}^{-}$reduction process.

The ORR catalytic behavior of FeP@PNC- $T$ was also evaluated in acidic media. The cathodic reduction current peaks in the $\mathrm{CV}$ measurements were found at $0.553,0.074,0.468$ and $0.457 \mathrm{~V}$ in an $\mathrm{O}_{2}$-saturated $0.5 \mathrm{M} \mathrm{H}_{2} \mathrm{SO}_{4}$ solution for $\mathrm{Pt} / \mathrm{C}$, FeP@PNC-800, FeP@PNC-900 and FeP@PNC-1000, respectively. Fig. 6b and Table S5 $\uparrow$ show that FeP@PNC-900 had significantly high ORR activity and its half-wave potential was only $60 \mathrm{mV}$ negative than that found for the Pt/C catalyst ( $0.547 \mathrm{~V}$ vs. $\mathrm{Ag} / \mathrm{AgCl})$. In addition, the ORR current density $(J)$ with FeP@PNC-900 measured at 1600 rpm was larger than those with $\mathrm{Pt} / \mathrm{C}$ at high potential regions $(>0.4 \mathrm{~V})$. The $\mathrm{K}-\mathrm{L}$ plots (Fig. 6d) for FeP@PNC-900 derived from Fig. 6c also exhibited good linear relationships, suggesting a first-order reaction towards the dissolved $\mathrm{O}_{2}$. Based on Fig. $6 \mathrm{~d}$, the electron transfer number was calculated to be around 4 over the potential range from $0 \mathrm{~V}$ to $0.20 \mathrm{~V}$, implying a four-electron ORR process in $0.5 \mathrm{M} \mathrm{H}_{2} \mathrm{SO}_{4}$ solution. These facts verified that FeP@PNC-900 can efficiently reduce oxygen in a direct four-electron pathway in both alkaline and acidic media.

It is reported that the integration of heteroatoms can break the electroneutrality of the carbon surface structure, reduce the adsorption barrier, and facilitate the oxygen adsorption process. ${ }^{51}$ In this study, the $\mathrm{N}$ and $\mathrm{P}$ dual-doping in the carbon nanosheets should effectively disturb the electroneutrality of the carbon surface. Furthermore, the effective utilization of the inhomogeneous electronic structures of the doped carbon materials will be favorable towards the reduction process of the oxygen molecules.
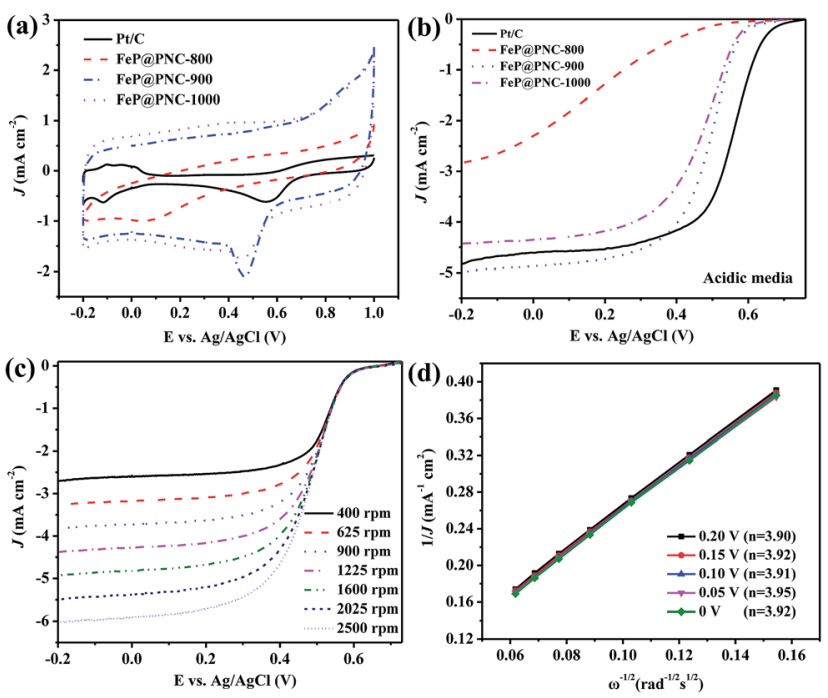

Fig. 6 (a) The CV curves obtained for the FeP@PNC-T samples prepared at different carbonization temperatures and the commercial $\mathrm{Pt} / \mathrm{C}$ catalyst in an $\mathrm{O}_{2}$-saturated $0.5 \mathrm{M} \mathrm{H}_{2} \mathrm{SO}_{4}$ solution at a scan rate of $10 \mathrm{mV} \mathrm{s}^{-1}$. (b) The LSVs of FeP@PNC-T and Pt/C at a scan rate of $5 \mathrm{mV}$ $\mathrm{s}^{-1}$ and a rotation rate of $1600 \mathrm{rpm}$. (c) The LSV curves obtained for FeP@PNC-900 at a rotation rate from 400 to $2500 \mathrm{rpm}$. (d) The $\mathrm{K}-\mathrm{L}$ plots and electron transfer number (in the legend) of the FeP@PNC900 catalyst in an $\mathrm{O}_{2}$-saturated $0.5 \mathrm{M} \mathrm{H}_{2} \mathrm{SO}_{4}$ solution.

To investigate the impact of FeP NPs embedded in the $\mathrm{N}$ and P dual doped carbon nanosheets in the ORR, the FeP@PNC-900 catalyst was further ground by ball-milling to destroy the protective carbon shells around the iron nanoparticles. After the milling step, the catalyst was leached in $0.5 \mathrm{M} \mathrm{H}_{2} \mathrm{SO}_{4}$ at $90^{\circ} \mathrm{C}$ for $12 \mathrm{~h}$ to remove or substantially diminish the FeP NPs. The resulting sample was named FeP@PNC-900-BL. Fig. S4 and Table S2 $\uparrow$ show that the total Fe content of FeP@PNC-900 was 1.24 at $\%$, while the value decreased to 0.78 at $\%$ for FeP@PNC900-BL. Moreover, the significant decrease in the $\mathrm{P} 2 \mathrm{p}_{3 / 2}$ peak (129.6 eV; 29.08 at\% and 5.60 at\% for FeP@PNC-900 and FeP@PNC-900-BL, respectively; Fig. S3c, and S5c †) clearly demonstrates that few FeP NPs remained in the sample. The TEM image (Fig. S6†) further confirmed that less FeP NPs were found after the acid leaching step. As a result, the FeP@PNC900-BL showed a decreased ORR activity in both alkaline and acid media (Fig. 7). The abovementioned results demonstrate
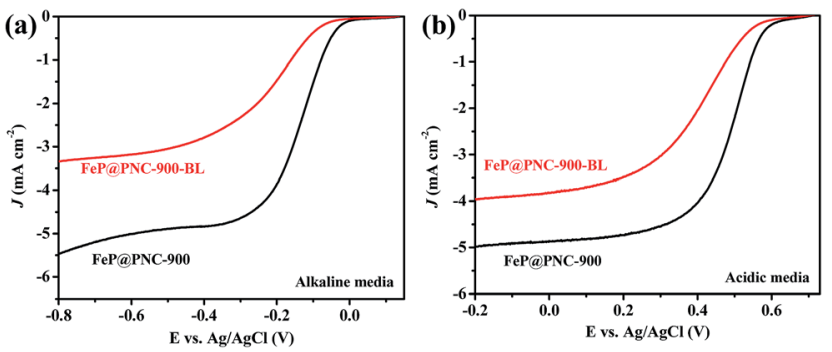

Fig. 7 The LSVs of FeP(APNC-900 and FePAPNC-900-BL at a scan rate of $5 \mathrm{mV} \mathrm{s}^{-1}$ and a rotation rate of $1600 \mathrm{rpm}$ in an $\mathrm{O}_{2}$-saturated (a) $0.1 \mathrm{M} \mathrm{KOH}$ and (b) $0.5 \mathrm{M} \mathrm{H}_{2} \mathrm{SO}_{4}$ solution, respectively. 
the significant effects of the embedded FeP NPs on the ORR process. Although the encased FeP NPs seemed not to be in direct contact with the reactants during the ORR process, they still played a key role in the catalysis. A previous report by $\mathrm{Hu}$ et al. showed that encased $\mathrm{Fe}_{3} \mathrm{C}$ NPs play a synergetic role in activating the surrounding graphitic layers, making the outer surface of the carbon layer active towards the ORR. ${ }^{31}$ Combined with this, the high activity of FeP@PNC-900 in the ORR can be attributed to the presence of the synergetic effects between the FeP NPs and outer heteroatom doped carbon layer.

Based on the structural characterization and electrochemical tests, it can be inferred that the degree of graphitization in carbon, the specific surface area and nitrogen and iron content are factors that contribute to the electrocatalytic properties of the catalysts. Increasing the pyrolysis temperature from 800 to $900{ }^{\circ} \mathrm{C}$ increased the degree of graphitization in the carbon substrate, as well as increased the surface area. However, further increasing the temperature to $1000{ }^{\circ} \mathrm{C}$ resulted in a decreased doped nitrogen content, surface area and iron content. A suitable pyrolysis temperature is very important to control the balance between all the structural factors, and consequently the balance between the catalytic active site density and electron conductivity is in favor of the ORR. The catalyst obtained at a pyrolysis temperature of $900{ }^{\circ} \mathrm{C}$ exhibited the highest ORR catalytic activity in both alkaline and acidic conditions, which is very important for an ORR electrocatalyst for practical applications.

A high tolerance towards fuel oxidation during the cathodic reactions is of great importance in developing low-temperature fuel cells. The impact of methanol on the cathodic current was observed in the chronoamperometric responses on the $\mathrm{Pt} / \mathrm{C}$ and FeP@PNC-900 catalysts in $\mathrm{O}_{2}$-saturated $0.1 \mathrm{M} \mathrm{KOH}$ and $0.5 \mathrm{M}$ $\mathrm{H}_{2} \mathrm{SO}_{4}$ solutions, respectively (Fig. $8 \mathrm{a}$ and b). For $\mathrm{Pt} / \mathrm{C}$,
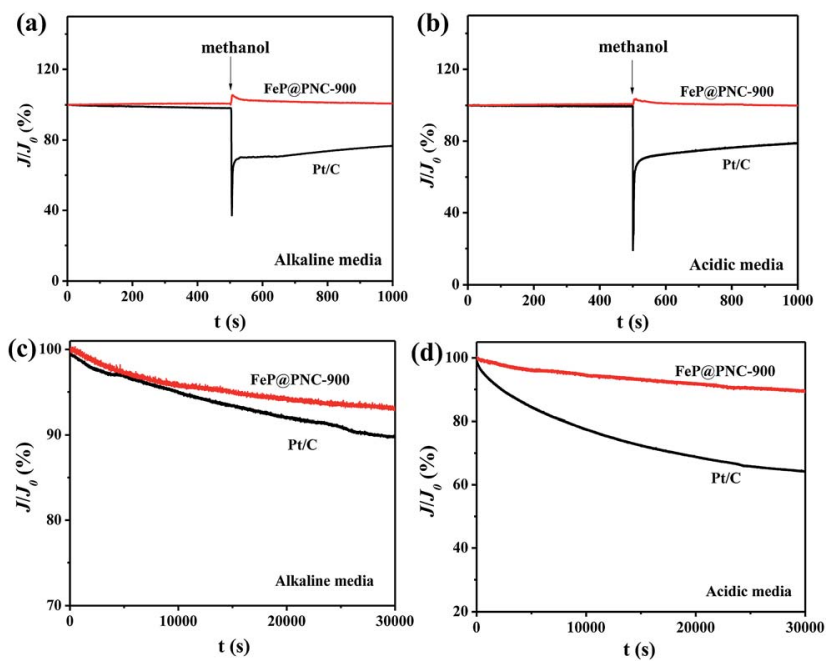

Fig. 8 The chronoamperometric responses during the ORR on the FeP@PNC-900 catalyst and commercial Pt/C catalyst modified electrodes in $\mathrm{O}_{2}$-saturated (a) alkaline media and (b) acid media, respectively. Durability test of the FeP@PNC-900 and commercial Pt/C catalysts at a rotation speed of $1600 \mathrm{rpm}$ with an applied potential of $-0.5 \mathrm{~V}$ in $\mathrm{O}_{2}-$ saturated (c) alkaline media and $0.3 \mathrm{~V}$ in (d) acidic media, respectively. a remarkable decrease in the ORR current density was observed due to methanol oxidation, i.e., the poisoning of the noble metal catalyst. In sharp contrast, a small activity change due to the addition methanol was observed with the FeP@PNC900 catalyst, suggesting its excellent tolerance ability to the methanol crossover effect.

In addition to its high activity and high selectivity, FeP@PNC-900 exhibited a strong durability as observed from its chronoamperometric response (Fig. 8c and d). A relative current of 93.14\% for the ORR on FeP@PNC-900 in 0.1 M KOH (Fig. 8c) and $89.82 \%$ in $0.5 \mathrm{M} \mathrm{H}_{2} \mathrm{SO}_{4}$ solution (Fig. 8d) was retained after 30000 s. In contrast, the ORR current on $\mathrm{Pt} / \mathrm{C}$ declined to approximately $89.72 \%$ in $0.1 \mathrm{M} \mathrm{KOH}$ and $64.14 \%$ in $0.5 \mathrm{M}$ $\mathrm{H}_{2} \mathrm{SO}_{4}$ solution measured under the same conditions. The high stability of FeP@PNC-900 can be attributed to the uniformly distributed iron nanoparticles with graphitized carbon outlayer embedded in the carbon matrix, avoiding the aggregation or dissolution of the iron phosphide NPs.

\section{Conclusions}

In summary, a high-performance non-precious metal phosphide catalyst used for the ORR in alkaline and acid medium was developed by pyrolysis of a mixture of $\left[\mathrm{Fe}(\mathrm{Phen})_{3}\right]^{2+}$, Mela and $\left(\mathrm{NH}_{4}\right)_{2} \mathrm{HPO}_{4}$ at different carbonization temperatures. The FeP@PNC catalysts were composed of $\mathrm{N}$ and $\mathrm{P}$ dual-doped carbon nanosheets and graphitized carbon coated FeP NPs. This catalyst exhibited excellent ORR activity and stability in both acidic and alkaline media. The good ORR performance of the catalyst is attributed to the synergetic effects between the embedded FeP NPs and the heteroatom-doped carbon structures, the porous structure as well as the good integration between the catalytic active site density and electron conductivity. Moreover, the FeP@PNC-900 catalyst exhibited excellent methanol-resistance and good durability towards the ORR in both alkaline and acidic media. Our study will be valuable in providing a novel approach for the design and development of low cost and abundant non-precious metal-containing heteroatom doped carbon materials used as cathode catalysts in PEMFCs.

\section{Acknowledgements}

This study was supported by NSFC (no. 21373116, 21421001 and 21534005), the Tianjin Natural Science Research Fund (13JCYBJC18300), RFDP (20120031110005) and the MOE Innovation Team (IRT13022) of China.

\section{Notes and references}

1 M. K. Debe, Nature, 2012, 486, 43-51.

2 I. E. L. Stephens, J. Rossmeisl and I. Chorkendorff, Science, 2016, 354, 1378-1379.

3 J. C. Park, S. H. Park, M. W. Chung, C. H. Choi, B. K. Kho and S. I. Woo, J. Power Sources, 2015, 286, 166-174.

4 Z. F. Li, L. Xin, F. Yang, Y. D. Liu, Y. Z. Liu, H. Y. Zhang, L. Stanciu and J. Xie, Nano Energy, 2015, 16, 281-292. 
5 D. Banham, F. X. Feng, T. Furstenhaupt, K. Pei, S. Y. Ye and V. Birss, Catalysts, 2015, 5, 1046-1067.

6 O. Diat and G. Gebel, Nat. Mater., 2008, 7, 13-14.

7 S. Y. Wang, E. Iyyamperumal, A. Roy, Y. H. Xue, D. S. Yu and L. M. Dai, Angew. Chem., Int. Ed., 2011, 50, 11756-11760.

8 J. Liang, Y. Jiao, M. Jaroniec and S. Z. Qiao, Angew. Chem., Int. Ed., 2012, 51, 11496-11500.

9 Y. J. Wang, N. N. Zhao, B. Z. Fang, H. Li, X. T. T. Bi and H. J. Wang, Chem. Rev., 2015, 115, 3433-3467.

10 Y. Nie, L. Li and Z. D. Wei, Chem. Soc. Rev., 2015, 44, 21682201.

11 G. A. Ferrero, A. B. Fuertes, M. Sevilla and M. M. Titirici, Carbon, 2016, 106, 179-187.

12 Q. Luo, L. Y. Chen, B. H. Duan, Z. Z. Gu, J. Liu, M. L. Xu and C. Y. Duan, RSC Adv., 2016, 6, 12467-12471.

13 M. Y. Ghotbi, B. Feli, M. Azadfalah and M. Javaheri, RSC Adv., 2015, 5, 92577-92584.

14 Y. L. Liu, C. X. Shi, X. Y. Xu, P. C. Sun and T. H. Chen, J. Power Sources, 2015, 283, 389-396.

15 M. A. Hoque, F. M. Hassan, M. H. Seo, J. Y. Choi, M. Pritzker, S. Knights, S. Y. Ye and Z. W. Chen, Nano Energy, 2016, 19, 27-38.

16 Y. Qiu, J. J. Huo, F. Jia, B. H. Shanks and W. Z. Li, J. Mater. Chem. A, 2016, 4, 83-95.

17 Y. Sun, J. Wu, J. H. Tian, C. Jin and R. Z. Yang, Electrochim. Acta, 2015, 178, 806-812.

18 M. Seredych and T. J. Bandosz, Carbon, 2014, 66, 227-233.

19 J. T. Zhang, Z. H. Zhao, Z. H. Xia and L. M. Dai, Nat. Nanotechnol., 2015, 10, 444-452.

20 J. Wu, Z. R. Yang, X. W. Li, Q. J. Sun, C. Jin, P. Strasser and R. Z. Yang, J. Mater. Chem. A, 2013, 1, 9889-9896.

21 R. Li, Z. D. Wei, X. L. Gou and W. Xu, RSC Adv., 2013, 3, 99789984.

22 H. N. Yang and W. J. Kim, Electrochim. Acta, 2016, 209, 430439.

23 H. J. Lu, Y. Li, L. Q. Zhang, H. N. Li, Z. X. Zhou, A. R. Liu, Y. J. Zhang and S. Q. Liu, RSC Adv., 2015, 5, 52126-52131.

24 Y. Z. Zhou, C. H. Yen, S. F. Fu, G. H. Yang, C. Z. Zhu, D. Du, P. C. Wo, X. N. Cheng, J. Yang, C. M. Wai and Y. H. Lin, Green Chem., 2015, 17, 3552-3560.

25 S. Y. Zhao, J. Liu, C. X. Li, W. B. Ji, M. M. Yang, H. Huang, Y. Liu and Z. H. Kang, ACS Appl. Mater. Interfaces, 2014, 6, 22297-22304.

26 C. H. Choi, S. H. Park and S. I. Woo, ACS Nano, 2012, 6, 70847091.

27 K. P. Gong, F. Du, Z. H. Xia, M. Durstock and L. M. Dai, Science, 2009, 323, 760-764.

28 L. J. Yang, S. J. Jiang, Y. Zhao, L. Zhu, S. Chen, X. Z. Wang, Q. Wu, J. Ma, Y. W. Ma and Z. Hu, Angew. Chem., Int. Ed., 2011, 50, 7132-7135.
29 J. W. Xiao, Y. Y. Xu, Y. T. Xia, J. B. Xi and S. Wang, Nano Energy, 2016, 24, 121-129.

30 B. K. Barman and K. K. Nanda, Green Chem., 2016, 18, 427432.

31 Y. Hu, J. O. Jensen, W. Zhang, L. N. Cleemann, W. Xing, N. J. Bjerrum and Q. F. Li, Angew. Chem., Int. Ed., 2014, 53, 3675-3679.

32 W. J. Jiang, L. Gu, L. Li, Y. Zhang, X. Zhang, L. J. Zhang, J. Q. Wang, J. S. Hu, Z. D. Wei and L. J. Wan, J. Am. Chem. Soc., 2016, 138, 3570-3578.

33 H. T. Wang, W. Wang, M. X. Gui, M. Asif, Z. Y. Wang, Y. Yu, J. W. Xiao and H. F. Liu, ACS Appl. Mater. Interfaces, 2017, 9, 335-344.

34 H. Osgood, S. V. Devaguptapu, H. Xu, J. Cho and G. Wu, Nano Today, 2016, 11, 601-625.

35 K. Parvez, S. B. Yang, Y. Hernandez, A. Winter, A. Turchanin, X. L. Feng and K. Mullen, ACS Nano, 2012, 6, 9541-9550.

36 Z. H. Wen, S. Q. Ci, Y. Hou and J. H. Chen, Angew. Chem., Int. Ed., 2014, 53, 6496-6500.

37 R. Z. Zhang, C. M. Zhang and W. Chen, J. Mater. Chem. A, 2016, 4, 18723-18729.

38 R. E. Davis, G. L. Horvath and C. W. Tobias, Electrochim. Acta, 1967, 12, 287-297.

39 J. H. Xue, L. Zhao, Z. Y. Dou, Y. Yang, Y. Guan, Z. Zhu and L. L. Cui, RSC Adv., 2016, 6, 110820-110830.

40 Y. L. Liu, X. Y. Xu, P. C. Sun and T. H. Chen, Int. J. Hydrogen Energy, 2015, 40, 4531-4539.

41 B. Wang, X. L. Li, B. Luo, J. X. Yang, X. J. Wang, Q. Song, S. Y. Chen and L. J. Zhi, Small, 2013, 9, 2399-2404.

42 X. G. Fu, Y. R. Liu, X. P. Cao, J. T. Jin, Q. Liu and J. Y. Zhang, Appl. Catal., B, 2013, 130, 143-151.

43 C. Z. Zhang, N. Mahmood, H. Yin, F. Liu and Y. L. Hou, Adv. Mater., 2013, 25, 4932-4937.

44 Q. X. Lai, Q. W. Gao, Q. Su, Y. Y. Liang, Y. X. Wang and Z. Yang, Nanoscale, 2015, 7, 14707-14714.

45 J. Li, Y. J. Song, G. X. Zhang, H. Y. Liu, Y. R. Wang, S. H. Sun and X. W. Guo, Adv. Funct. Mater., 2017, 27, 1604356.

46 Y. P. Zhu, X. Y. Xu, H. Su, Y. P. Liu, T. H. Chen and Z. Y. Yuan, ACS Appl. Mater. Interfaces, 2015, 7, 28369-28376.

47 J. Yang, H. Y. Sun, H. Y. Liang, H. X. Ji, L. Song, C. Gao and H. X. Xu, Adv. Mater., 2016, 28, 4606-4613.

48 Y. P. Zang, H. M. Zhang, X. Zhang, R. R. Liu, S. W. Liu, G. Z. Wang, Y. X. Zhang and H. J. Zhao, Nano Res., 2016, 9, 2123-2137.

49 Y. Y. Liang, Y. G. Li, H. L. Wang, J. G. Zhou, J. Wang, T. Regier and H. J. Dai, Nat. Mater., 2011, 10, 780-786.

50 K. J. J. Mayrhofer, D. Strmcnik, B. B. Blizanac, V. Stamenkovic, M. Arenz and N. M. Markovic, Electrochim. Acta, 2008, 53, 3181-3188.

51 D. W. Wang and D. S. Su, Energy Environ. Sci., 2014, 7, 576591. 